\title{
UM POUCO DA HISTÓRIA DA EDUCAÇÃO NO OESTE DO PARANÁ ${ }^{1}$
}

\author{
Ivo Oss Emer ${ }^{2}$
}

\section{RESUMO}

Este artigo trata da educação na região Oeste do Paraná, que teve sua ocupação e colonização, de forma mais significativa, a partir de 1930. A intensa colonização só ocorreu depois dos anos 1950, desencadeada pelas alterações econômicas e pelo consequente deslocamento das fronteiras agrícolas pelos excedentes populacionais, especialmente das chamadas colônias velhas de imigrantes europeus do sul do país. Essa população migrante tinha, por razões históricas e culturais, um elevado apreço pela escolarização de seus filhos e, consequentemente, pela escola. Na ausência de ações do poder público, os colonos construíram sua escola, a serviço de seus interesses e de sua cultura. Contudo, como veremos, na medida que o poder público foi construindo sua presença, a escola dos colonos, por diversas razões, tornou-se inviável.

Palavras-chaves: Colonização, Oeste do Paraná, História da Educação, Escola

\section{A LITTLE HISTORY OF EDUCATION IN WEST PARANÁ}

\begin{abstract}
ABSTRAT
This article deals with the education in western Paraná, which had its occupation and colonization, more significantly, in 1930. The intense colonization occurred only after the 1950s, triggered by economic changes and the consequent displacement of the agricultural frontier by the surplus population, especially the so-called old colonies of European immigrants from the south. This migrant population had, for historical and cultural reasons, a high appreciation for the schooling of their children and therefore the school. In the absence of actions of the government, the settlers built their school, to serve their interests and their culture. However, as we shall see, to the extent that the government was building its presence in the school of the settlers, for various reasons, became unviable.

Keywords: Colonization, Western Paraná, History of Education, School
\end{abstract}

\section{A primitiva escola no Oeste do Paraná}

Como a ocupação e colonização da região Oeste do Paraná ocorreram, exceto em alguns pontos esparsos da região, após 1930 e a colonização propriamente dita a partir do final da Segunda Guerra Mundial, consolidando-se nas décadas de 1950 e 1960, a escola da região Oeste do Paraná foi constituída no contexto amplo do desenvolvimento das forças produtivas nacionais, da divisão do trabalho determinado pelo modelo econômico urbano-industrial capitalista, da modernização do Estado e de seus serviços e da definição das classes sociais nas relações de produção.

Tais transformações têm início ainda durante a Primeira Guerra Mundial e se originam das alterações por ela desencadeadas na economia do país. Em razão do conflito, houve a impossibilidade de importação de diversos produtos de consumo, tais como banha, manteiga, sabão e, por incrível que pareça, madeira de pinho trazida da Escandinávia (o famoso pinho de Riga) para as fábricas de móveis do Rio de Janeiro e São Paulo. A falta de bens de consumo, até então importados, viabilizou a produção e o consumo dos chamados produtos coloniais. 
No mesmo período, o governo brasileiro definiu novas políticas de desenvolvimento, como a que foi denominada de "substituição das importações". Em consequência dessa política, o país passou por um primeiro surto de industrialização, gerando um primeiro processo de urbanização da população rural brasileira. A urbanização aumentou os mercados consumidores de alimentos, gerando, de imediato, a implantação de indústrias de processamento de gêneros alimentícios, ampliando as possibilidades de comercialização de excedentes da produção agrícola das regiões coloniais.

Neste contexto em transformação, de lutas dos colonos pela conquista da terra como meio de sobrevivência e de reprodução como produtores rurais de excedentes comerciais e de lutas pela conquista de espaço social e político, foi construída a escola e sua representação na região, e reivindicada junto aos poderes públicos e organizações religiosas, na forma da lei, como um direito de todos, ou, no mínimo, como um direito subjetivo de quem tinha consciência dele; numa perspectiva de entendimento de que a educação é uma instrumentalização necessária às práticas sociais.

Cabe agora, de modo amplo, analisar como foi gestada a escola dentro do processo de ocupação e colonização da região Oeste do Paraná com o objetivo de desvendar a maneira pela qual o interesse dos colonos se articulou com o poder político e outras instituições no atendimento à demanda por educação.

Uma questão fundamental é levar em conta que a demanda por educação é sempre do tamanho da necessidade sentida pela sociedade. Essa necessidade é sentida a partir do estágio do desenvolvimento das condições de existência, isto é, do tamanho da necessidade do saber fazer, do saber trabalhar para produzir os meios de vida. Quanto mais desenvolvida é uma sociedade, e mais complexas são as relações sociais que estabelece; quanto mais ciência e tecnologia são utilizadas nas máquinas, equipamentos e instrumentos de trabalho, maior é a necessidade sentida pela população por mais e mais educação.

$\mathrm{Na}$ tentativa de desvendar como foi pensada a escola no interior do processo histórico de ocupação e colonização do Oeste do Paraná, torna-se indispensável definir termos que identificam as formas de escolarização, modalidades de escola e suas práticas pedagógicas surgidas do interior dos grupos sociais pioneiros. Nas pesquisas realizadas em diferentes fontes documentais, depoimentos de antigos professores e alunos que passaram por processo de escolarização no período em foco, requerem que sejam estabelecidas algumas distinções ou esclarecimentos conceituais.

Uma primeira distinção é a prática da escolarização ou simples instrução sem a instituição escolar, uma escolarização informal, para crianças na faixa etária de escolarização; modalidade de instrução denominada, no presente trabalho, como Escolarização particular domiciliar. Esta prática de escolarização era exercida por alguém do grupo social estabelecido, que tinha disponibilidade e condições mínimas de ensinar, sem nenhum ato oficial, sem nenhuma regulamentação. Simplesmente, algumas crianças reuniam-se ao redor da mesa de refeições de uma residência para aprender ler, escrever e calcular - currículo e objetivos educacionais estabelecidos pelos pais. Essa prática de escolarização não pode ser confundida com a instrução dada pelos pais. Estes, quando escolarizados, ensinavam seus filhos a ler, escrever o próprio nome, de forma esporádica, em dias de chuva, sem sequência. Ao passo que a instrução Particular Domiciliar tinha regularidade, um sentido de escolarização, um sentido de processo de aprendizagem.

Uma segunda distinção é a Casa escolar particular construída e mantida pelo grupo social pioneiro em suas respectivas localidades. Esta modalidade de instrução era semelhante à anterior no que se refere às práticas educacionais, e instituída também de forma não oficial. Mas tinha significativas diferenças. Era construída para ser o local da 
instrução e para ampliar a capacidade de atendimento a mais crianças - que a mesa de refeições já não comportaria. Do professor era exigida uma melhor qualificação, isto é, deveria ensinar mais que na escolarização Domiciliar; a Casa Escolar deveria funcionar tecnicamente bem. Estas duas modalidades particulares de educação têm muito de semelhante com as que existiram no sul do país nas colônias de imigrantes europeus.

$\mathrm{Na}$ ocupação e colonização do Oeste do Paraná, a Casa Escolar Particular mais comum foi a Escola dos colonos. Este tipo de escola originou-se da própria índole dos descendentes de imigrantes europeus. Os grupos coloniais não esperavam que o poder público resolvesse o problema da educação; eles construíam sua escola, contratavam e pagavam seu professor e produziam a educação por eles percebida como necessária.

Uma terceira distinção é a Casa escolar pública dos núcleos urbanos, onde já existia alguma presença do serviço público. Esta modalidade escolar, criada por ato oficial do poder público municipal, quase sempre assumindo a Casa Escolar existente, ou construindo onde não existisse e, em ambos os casos, pagando o professor. Como uma escola oficial, os alunos das Casas Escolares Públicas eram submetidos aos exames públicos, elaborados pelos órgãos educacionais públicos para comprovação da escolaridade primária. Se comprovasse escolarização de nível primário, recebia o diploma - uma garantia de conquista de espaço de trabalho, especialmente no serviço público. Desde essa época, um certificado de escolarização contribuía para conquista de espaço social, no contexto da já ampla divisão do trabalho.

Por fim, a quarta distinção, o Grupo escolar público. Essa modalidade educacional distingue-se fundamentalmente por ser um tipo de escola construída em núcleos de povoamento mais desenvolvidos e pela forma de funcionamento. Se nas modalidades anteriores era aprender a ler, escrever e calcular e, depois da oficialização da casa escolar, a comprovação da escolarização mediante exame, no grupo escolar passou a existir a preocupação em "passar" para a série seguinte, num processo gradual de comprovação de conhecimentos dos conteúdos definidos pelo "sistema" educacional como requisito de cada série. Mesmo que o Grupo Escolar funcionasse na anterior Casa Escolar, o trabalho do professor foi dividido em séries e o aluno comprovaria escolarização primária após aprovação nos exames da última série. Antes o professor tinha controle sobre todo o processo de aprendizagem de seus alunos; agora passa a ter o controle apenas dos alunos na série em que atua. Isto não deixa de ser uma divisão social do trabalho, dentro dos moldes da divisão do trabalho no modo capitalista de produção. A organização da escola passa a reproduzir a organização da sociedade.

Para entender como foram construídas as estruturas e as formas educacionais na região, a seguir será analisado como foi gestada e como evoluiu a escola a partir do interior dos núcleos de ocupação e colonização pioneiros do Oeste do Paraná, observando uma certa sequência cronológica. Contudo, a modalidade da escola pode ser uma ou outra, dependendo dos contextos históricos e das especificidades de cada núcleo populacional. Algumas dessas modalidades de escola, ou as razões de sua existência, repetem-se em diferentes períodos históricos. Isto significa dizer que a determinação do tipo de escola não tem seus fundamentos a partir de aspectos cronológicos, mas sim das condições sociais, da presença ou ausência do poder público ou dos níveis de satisfação ou insatisfação em relação à qualidade técnica da escola, envolvendo também interesses bem específicos do grupo colonial (disciplina, ensino religioso, canto sacro, seriedade do ensino, "moralidade" na conduta de professores). Essa afirmação fundamenta-se no fato de que, ao longo do processo histórico regional, quando a escola pública não atendia em quantidade ou qualidade os interesses de segmentos sociais dinâmicos e organizados, voltaram a 
construir, com outras características, novas modalidades de escolas particulares, especialmente com vínculos confessionais.

Em Foz do Iguaçu, núcleo pioneiro da ocupação nacional regional, desde os tempos da Colônia Militar, existiu por parte dos militares e funcionários do fisco, a preocupação com a escolarização de seus filhos. Esse segmento social resolveu o problema da instrução a partir de seu próprio grupo social. Essa instrução era quantitativamente muito restrita, só para filhos de funcionários dos postos mais importantes, na modalidade de Escola Particular Domiciliar. Como essas crianças eram filhas de funcionários do governo, cujo papel era exercido a partir de uma escolarização mínima, viam na instrução a possibilidade de criar as condições de seus filhos galgarem, no futuro, algum posto na administração pública. O interesse dessas famílias em contratar os serviços de escolarização de seus filhos revela o desejo de reprodução de suas condições sociais e um nível de consciência de classe na perspectiva da ideologia liberal, isto é, na luta pela conquista de espaço social, venceria quem tivesse melhores condições, a partir da escolarização, mesmo que realizada em espaço doméstico e de maneira informal.

No período de 1889, ano da criação da Colônia Militar, até 1912, ano de sua extinção, não existiu Casa Escolar ou algum outro tipo de escola em Foz do Iguaçu. As crianças de famílias brasileiras com recursos financeiros, mas que não pertenciam ao grupo de funcionários do governo, buscavam escolarização fora de Foz do Iguaçu, em outros centros urbanos e até nos países vizinhos ${ }^{3}$.

A partir de 1914, a história de Foz do Iguaçu passou por consideráveis transformações. A primeira foi, apesar das precariedades, a criação do município. A segunda, a decisão do governo em combater o contrabando na fronteira, aumentando consideravelmente o número de agentes do fisco. Tanto um fato quanto o outro, criou novas oportunidades de trabalho para setores sociais escolarizados e que exigiriam escolarização para seus filhos. A soma desses fatores, isto é, aumento da população e, consequentemente, do número de crianças a serem escolarizadas, tornou inviável o atendimento na modalidade de instrução Particular Domiciliar, exigindo uma resposta da administração municipal. Cruzando diferentes informações levantadas na pesquisa, foi possível concluir que entre os anos 1915 e 1916 passou a existir Casa Escolar Pública em Foz do Iguaçu, construída e mantida pelo município. Como ocorria nas demais regiões do Estado, a instrução produzida na Casa Escolar era extremamente precária. Talvez em razão dessa precariedade da instrução produzida pela Casa Escolar tenha continuado em Foz do Iguaçu, a instrução Domiciliar Particular até a instalação do Grupo Escolar em $1928^{4}$.

Contudo, o desenvolvimento educacional de Foz do Iguaçu está relacionado com a articulação de outros fatores de importância nas representações sociais daquele núcleo populacional. Até 1918, a população católica de Foz do Iguaçu recebia, uma vez por ano, assistência religiosa de sacerdotes de Posadas, capital da província argentina de Misiones. Apenas muito esporadicamente passava algum padre da paróquia de Guarapuava, à qual pertencia Foz do Iguaçu. Como Foz do Iguaçu já tinha sido elevada à categoria de sede de município, a questão da assistência religiosa também fazia parte das preocupações da população local e da Igreja. Em razão da distância, da precariedade dos transportes e das estradas, as autoridades eclesiásticas julgaram conveniente criar a paróquia de Foz do Iguaçu. Diante das dificuldades econômicas para a instalação da paróquia, o bispo de Curitiba pediu auxílio ao governo do Estado. Este comprometeu-se em repassar subvenções e até salários aos padres, mas, em contrapartida, a paróquia deveria construir e dirigir o Grupo Escolar em Foz do Iguaçu 5 .

Em 1923, foi instalada a paróquia e nomeado o primeiro vigário, um sacerdote alemão da Congregação do Verbo Divino, Padre Guilherme Maria Tilecks. Para 
cumprimento do acordo com o Estado, mesmo antes da construção do Grupo Escolar, o Padre Guilherme passou a lecionar na Casa Escolar. Para o desempenho de suas atividades, recebeu a ajuda de outros dois padres e de um irmão de sua congregação (Padre João Progzeba, Padre Paulo Schneider e Irmão Bianchi) ${ }^{6}$. Em 1928, entrou em funcionamento o Grupo Escolar, em prédio novo, sob a direção do Monsenhor Guilherme ${ }^{7}$, com a denominação Grupo Escolar Bartolomeu Mitre. O Grupo Escolar passou a ter como professores dois padres (Padre João Worth e Padre José Winks) e duas professoras escolhidas pelos padres entre a população de Foz do Iguaçu (Aretusa Reis da Silva e Francisca Correia Schimmelpfeng). Em 1930, o Grupo Escolar passou para a administração estadual, sob a direção de professores nomeados e pagos pelo Estado ${ }^{8}$.

Mesmo que em Santa Helena houvesse colonos assentados desde 1921 pela Firma Alegretti e, depois de 1926, pela Companhia Espéria e esses colonos fossem italianos ou descendentes de italianos, tradicionalmente católicos, apenas em 1923, receberam, pela primeira vez, assistência religiosa, após a criação da paróquia de Foz do Iguaçu. Os colonos de Santa Helena conseguiram ter capela em 1929, uma obra reivindicada junto à Companhia Espéria e construída por eles em terreno da companhia. A organização da capela seguiu o modelo das colônias de imigrantes italianos do Rio Grande do Sul, isto é, foi constituída uma diretoria, à qual caberia a administração da capela e a promoção de festas para arrecadar recursos destinados à realização de obras complementares ${ }^{9}$. A diretoria da capela, mesmo havendo reivindicação da escola, preferiu dar prioridade à construção do salão de festas, justamente por ser um meio indispensável de arrecadação de recursos e local de encontro dos colonos tanto para lazer como para discussão e encaminhamento de soluções para seus problemas coletivos.

Os colonos de Santa Helena, além da extrema dificuldade de comunicação com as localidades próximas - dispunham praticamente apenas do rio Paraná - a colônia tinha também peculiaridades. Neste período não existia um núcleo populacional, tão somente os barracões da administração e o porto de Santa Helena, de propriedade da empresa Domingos Barthe, que não fazia parte da colonização. Os colonos viviam isolados em seus lotes rurais, distanciados entre si, e com problemas de subsistência, em razão das sérias dificuldades de escoamento da produção. Esses fatores complicavam a solução para a escolarização de seus filhos.

A conjugação desses fatores explica também porque em Santa Helena, nesse período, não tenha sido encontrado nenhum relato de instrução Particular Domiciliar, na modalidade tratada acima. Mas isso não exclui ou invalida a instrução "doméstica" realizada pela família que, comprovadamente, existiu. Os pais alfabetizados, especialmente nos dias de chuva ou à noite, utilizando carvão e tábuas ou lápis e papel de embrulho de mercadorias, ensinavam as letras a seus filhos, a escrever o próprio nome, de forma esporádica, não sistematizada, completamente distinta da instrução Particular Domiciliar, anteriormente caracterizada ${ }^{10}$.

Nos primeiros anos de 1930, o grupo colonial conseguiu que o Padre José Winks, liberado dos compromissos com o Grupo Escolar de Foz do Iguaçu, estabelecesse residência permanente em Santa Helena. Como já era projeto dos colonos lá estabelecidos, a paróquia seria fundada desde que houvesse terreno repassado para a Diocese e escriturado como propriedade da Igreja. Por não ter havido acordo entre o grupo colonial e autoridades da Igreja com a Companhia Espéria, esta negou-se a fornecer escritura do terreno ocupado pela capela e salão de festas, tornou-se inviável a criação da paróquia. Em outubro do mesmo ano, o padre recebeu ordens superiores para retornar a Foz do Iguaçu ${ }^{11}$.

Durante sua permanência em Santa Helena, além das atividades estritamente religiosas, o Padre José Winks dava aula para um grupo de crianças no salão de festas. 
Ensinava "as primeiras letras e um pouco de aritmética básica, além do ensino religioso"12 Esses foram os primeiros meses de funcionamento de algum tipo de escola em Santa Helena, sonho que se desfez junto com a tentativa do núcleo colonial de constituir sua paróquia.

Em 1936, o Porto de Santa Helena e a Companhia Domingos Barthe foram desativados. Em 1942, em razão da guerra, italianos e alemães foram expulsos da fronteira, reduzindo ainda mais a pequena população de Santa Helena. Na mesma data, a Companhia Espéria foi encampada pelo governo do Estado. Esta entrou na Justiça, mediante recurso. O caso só foi resolvido em 1950. Depois de solucionado o caso na Justiça, as terras que pertenceram à Companhia Espéria foram compradas por empresas colonizadoras do sul do país.

A colonização de Santa Helena só foi retomada na década de 1950, já no contexto do amplo movimento de colonização do Oeste do Paraná. A luta pela criação da paróquia de Santa Helena só terminou em 1961. Antes da paróquia, Santa Helena conseguiu sua escola, em 1956, num contexto histórico diferente de suas lutas anteriores.

Mas antes de 1956, antes da existência da escola, houve escolarização em Santa Helena. Os colonos assentados na década de 1950, além de serem migrantes num contexto histórico diferenciado dos pioneiros, tinham outras condições, tanto econômicas quanto culturais. Durante a década de 1940 e primeiros anos da década de 1950, o sistema educacional do Rio Grande do Sul e de Santa Catarina atingiu grande parte das populações rurais das antigas colônias de imigrantes. Membros das famílias assentadas em Santa Helena tinham passado por escolarização primária em suas regiões de origem. Até as colonizadoras desse período tinham outros conceitos na divisão das glebas em lotes rurais, prevendo a produção e o escoamento da produção. Levavam em conta a topografia e a criação de infraestrutura necessária ao progresso produtivo. Entre os lotes rurais eram reservados espaços para a construção de vias de acesso, chamados travessões.

Nos chamados travessões de Santa Helena foram construídas capelas em homenagem a santos de suas devoções em terreno cedido por um dos colonos situado em um ponto de acesso favorável à maioria. Essas capelas eram utilizadas como local de escolarização de crianças moradoras das proximidades ${ }^{13}$. A escola, informal e sem nenhum ato oficial, era mantida pelo próprio grupo colonial que, coletivamente, construiu a capela. A professora, normalmente uma adolescente do grupo colonial razoavelmente escolarizada, dentro de suas possibilidades, instruía as crianças do travessão, utilizando os mais criativos recursos didáticos existentes no local. Segundo diversos relatos, substituindo quadro e giz, por papelão e carvão ${ }^{14}$.

Dentro do novo contexto das colonizadoras do final da década de 1940 e 1950, havia a preocupação com a criação dos serviços básicos exigidos pelos colonos. As colonizadoras reservavam áreas para os futuros núcleos urbanos e instalação dos serviços de que as próprias colonizadoras necessitavam. A perspectiva da criação de infraestruturas era fator preponderante para atrair novos compradores de lotes rurais. A existência de escola ou a perspectiva de sua imediata instalação constituía-se em um dos itens preponderantes, entre outros, para aquisição de terras pelos colonos do sul, premidos a migrar pelas condições estruturais nas velhas colônias. Considerados esses fatores, os gerentes das colonizadoras, em função de seus próprios negócios, nos contatos com o serviço público, articulavam a conquista dos serviços reivindicados pelos colonos. A principal colonizadora de Santa Helena reservou e planejou a área urbana e aí foi instalada a primeira escola oficial, o grupo escolar estadual. Apenas após a emancipação do município foram criadas as escolas municipais rurais, grande parte delas no mesmo local onde já existia a escola de travessão dos colonos. O município construía a escolinha rural 
ao lado da já existente capela do travessão, assumindo a responsabilidade pela manutenção e pelo pagamento da professora ${ }^{15}$.

Guaíra tem toda uma história ligada à Companhia Mate Laranjeira ${ }^{16}$. A essa companhia, Guaíra deve sua fundação, em 1909, e seu desenvolvimento inicial nas décadas seguintes. Depois de 1917, ano em que a companhia melhorou a estrada de ferro ligando Guaíra ao Porto Mendes e implantou a tração por locomotiva, a localidade passou a ter importância, exigindo sucessivas melhorias. Guaíra foi transformada em sede social da empresa Mate Laranjeira, um núcleo urbano planejado, com traçado de ruas, avenidas, arborização, boas construções para alojar seus funcionários categorizados; dispunha de médico e farmácia. O porto e a ferrovia eram movimentados. Ao longo da ferrovia, a Companhia Mate Laranjeira implantou uma linha telegráfica e dispunha de um sistema particular de correios ${ }^{17}$. Após 1920, com a construção e entrada em funcionamento do Porto Epitácio, no estado de São Paulo, que estabelecia a ligação com o Porto de Guaíra, aumentou o movimento de pessoas e cargas, tornando possível o comércio de produtos da indústria paulista no Oeste do Paraná ${ }^{18}$.

Como era uma companhia de origem brasileira, com sede no Brasil e de sua diretoria participava um bom número de brasileiros, contava, também, com trabalho de brasileiros com um certo nível de escolarização, capazes de fazer anotações e cálculos contábeis do movimento do porto. Esses trabalhadores moravam em Guaíra com suas famílias e constituíam segmentos sociais que valorizavam a escolarização e não se conformavam com que seus filhos não tivessem escola.

Mesmo que não tenha sido obtida a data precisa, pelo caminho da confrontação de informações, tudo indica que nos primeiros anos da década de 1920 tenha sido iniciada a escolarização em Guaíra, na modalidade Particular Domiciliar. Esse fato foi comprovado, visto que foi obtida a informação de que os diretores da Mate Laranjeira incentivaram e apoiaram uma senhora que dava aulas a um grupo de crianças, em sua residência, sentados à mesa de refeições. $O$ interesse da Mate Laranjeira pela escolarização devia-se especialmente a suas carências de mão-de-obra qualificada para o trabalho nos escritórios, para fazer assentamentos e transcrições nos livros de contabilidade da companhia ${ }^{19}$.

Possivelmente, essa modalidade de escolarização tenha sido considerada insuficiente para suprir as necessidades de mão-de-obra da Mate Laranjeira. Esta possibilidade está relacionada ao fato de que, em 1928, Francisco Mendes Gonçalves, um dos diretores da companhia, determinou a construção e manutenção de uma Casa Escolar em Guaíra ${ }^{20}$ e a professora não foi escolhida entre quem já ensinava, mas contratada em Curitiba, uma normalista formada. Contudo, essa professora permaneceu pouco tempo em Guaíra. Foi substituída por Marina Marcondes Suarez, moradora da localidade e considerada a primeira professora de Guaíra ${ }^{21}$. Outra hipótese que poderia explicar a construção e manutenção da casa escolar pela Mate Laranjeira poderia ser também, como ocorreu em outros pontos da região, a reivindicação de escola para um número de crianças superior à capacidade de atendimento na modalidade Particular Domiciliar.

Em 1942, ainda sob a responsabilidade de manutenção da Mate Laranjeira, a Casa Escolar foi transformada em Grupo Escolar. Em toda a região, as Casas Escolares só foram transformadas em Grupos Escolares quando houve um sensível crescimento populacional e a ampliação da presença do poder público. Não há indicação de que isso tenha ocorrido em Guaíra no período. Quando criados, os Grupos Escolares, de imediato, passavam para a competência do Estado. Não foi constatado que esse fato tenha ocorrido em Guaíra. Segundo consta, havia muitas queixas da população quanto ao nível técnico da escolarização produzida pela Casa Escolar de Guaíra. Talvez a Mate Laranjeira tenha adotado o sistema de Grupo Escolar na tentativa de melhorar as condições da 
escolarização. Já no ano seguinte, com a criação do Território Federal do Iguaçu, o Grupo Escolar passou para a administração federal. Com a extinção do Território Federal em 1946, a administração do Grupo Escolar passou para o município de Foz do Iguaçu. Mais uma vez, diferente do geral da região. Em 1951, com a criação do município de Guaíra, o Grupo escolar foi estadualizado ${ }^{22}$.

Em Catanduvas, embora lá tenha se estabelecido população desde a época da criação do posto de abastecimento dos militares fundadores da Colônia Militar de Foz do Iguaçu (1889), só passou a existir alguma forma de escolarização no final da década de 1920, com peculiaridades, até certo ponto, inéditas, em toda a região Oeste do Paraná. A primitiva população, assentada em Catanduvas pelos militares, era constituída por caboclos paranaenses, isto é, por uma população que vivia nas matas próximas a Guarapuava. Esse segmento social, por razões histórico-culturais, não reivindicou escolarização, nem por eles foi tomada alguma iniciativa nesse sentido.

Mesmo que nos anos anteriores Catanduvas já fosse uma referência no contexto regional tanto para militares como para o sistema de conservação da Rodovia Estratégica, apenas no final da década de 1920, o núcleo populacional lá estabelecido teve alterações em sua realidade social. Essas alterações tiveram origem em três fatores. O primeiro foi a instalação de postos telegráficos (General Rondon - combate à Coluna Prestes 1925) ao longo da rodovia até alguns portos do rio Paraná, interligando a região. Catanduvas passou a ser um entroncamento de linhas telegráficas, exigindo a presença de operadores do sistema, que lá se estabeleceram com suas famílias. O segundo fator foi o deslocamento de pecuaristas de Guarapuava e de outras localidades do Paraná para Catanduvas. Esse segmento social, bem relacionado com os grupos políticos do Paraná tradicional, teve facilidades em requerer e ocupar terras públicas do Estado. Aí implantaram fazendas, ocupando mão-de-obra para a derrubada da mata, cultivo de milho, criação de porcos no sistema de safra; criação de equinos e muares, importantes para o transporte na época. E, por último, o deslocamento de descendentes de imigrantes, pequenos produtores rurais de Santa Catarina (Canoinhas, Moema, e outras localidades - 1932) e das colônias de imigrantes do Paraná, com níveis de civilização diferentes dos caboclos, que iniciaram o processo de ocupação das terras para produção agrícola mercantil, com trabalho familiar.

Os fazendeiros, por disporem de recursos, mandavam seus filhos para a escola em Guarapuava; as filhas internas, os filhos em casa de parentes ou conhecidos. Os outros dois segmentos sociais, constituídos por funcionários do governo e colonos descendentes de imigrantes, com poucos recursos, passaram a reivindicar escola para seus filhos.

A alternativa encontrada para o problema da escolarização em Catanduvas é que constitui o aspecto inédito na região. Uns poucos fazendeiros, politicamente bem relacionados com Guarapuava, alguns funcionários públicos e comerciantes constituíram uma Célula Integralista em Catanduvas. Essa Célula de Ação Integralista construiu a Casa Escolar, fornecia material didático de boa qualidade, exigia que as datas cívicas fossem comemoradas e cantado o hino nacional, supervisionava a educação física, ensinava marcha e pagava a professora. Em 1929, contando com Casa Escolar bem construída e uma professora formada na Escola Norma Regional Nossa Senhora do Belém de Guarapuava, foi iniciada a educação escolar em Catanduvas ${ }^{23}$. Contudo, esta escola teve um curto período de funcionamento. A professora decidiu morar com os pais na fazenda, abandonando as atividades na Casa Escolar, em 1931. No ano seguinte já não havia mais escola em Catanduvas. A desativação da escola não foi apenas por falta de professora, mas especialmente em razão do novo traçado da estrada executado na época, deixando Catanduvas afastada da rodovia. As perspectivas de desenvolvimento tornaram-se maiores em Cascavel. Em decorrência do novo traçado da rodovia, os serviços públicos existentes 
em Catanduvas foram transferidos para Cascavel, onde foi instalada a Central de Correios e Telégrafos e foram divulgados planos de governo para o desenvolvimento da localidade. Quem tinha interesses em dedicar-se a atividades urbanas tratou de transferir-se de Catanduvas para Cascavel. Até famílias de agricultores, descendentes de poloneses, já instalados em Catanduvas, transferiram-se para Cascavel, onde já existia um grupo polonês radicado. "A escola de Catanduvas foi interrompida porque quem se interessava pela educação de seus filhos veio para Cascavel." 24

No período de 1932 a 1943, época em que Catanduvas não mais contou com escola, existiu alguma forma de escolarização. As famílias de pequenos comerciantes e de outras atividades urbanas davam um jeito para que seus filhos aprendessem ler, escrever e fazer contas. "Quando comecei a dar aula (1943), a gente encontrava um ou outro que já sabia alguma coisa, muito pouco..." 25

Catanduvas, apesar do êxodo populacional na década de 1930, sempre contou entre sua população, com fazendeiros, comerciantes e tropeiros, vinculados aos políticos do Paraná tradicional, que se interessavam pela localidade. Talvez por essas razões, Catanduvas continuou a ser uma localidade de prestígio. Em 1943, estava concluída a construção do Grupo Escolar Anita Ribas, mantido pelo Estado, com professores nomeados e pagos pelo Estado. $\mathrm{O}$ nome da escola foi dado em homenagem à esposa do interventor Manoel Ribas que governou o Paraná no período de 1931 até a queda de Getúlio Vargas. "Anita Ribas visitou o Grupo, mandava material, mapas, bandeira... " 26

Diferentemente de outras localidades do Oeste do Paraná, que só tiveram escola muito tempo depois da ocupação, Cascavel passou a contar com escola apenas dois anos após a fixação dos primeiros moradores. A rapidez como foi constituída a escola, deveu-se especialmente às características humano-culturais de sua população. $\mathrm{O}$ grupo pioneiro era constituído por comerciantes e suas famílias, acompanhado de caboclos, trabalhadores rurais, e de descendentes de imigrantes poloneses, com diversos ramos de atividade. Tanto os comerciantes como os descendentes de imigrantes viam na escolarização aspectos práticos para as relações sociais, na humanização de si próprios e de sua cultura. A essa população inicial juntaram-se outros segmentos sociais constituídos por funcionários dos Correios e Telégrafos e da Comissão de Estradas (estabeleceram um acampamento em Cascavel) que reconheciam a importância da escolarização. Como acontecia em outros pontos da região, a população estabelecida em Cascavel também construiu sua capela, em homenagem a Nossa Senhora Aparecida. Em 1932, a capela passou a ser utilizada para escolarização de crianças, de maneira informal, na modalidade de Casa Escolar Particular. Nos três primeiros anos, a escola foi mantida pela população local e os primeiros professores (Aníbal Lopes da Silva, Sandálio dos Santos) tinham vínculos com a Comissão de Estradas; outros eram funcionários públicos.

A partir de 1935, mesmo que a escola funcionasse no mesmo local e mantivesse as mesmas condições, assumiu uma professora, que passou a ser paga pelo município de Foz do Iguaçu, sem elevação da escola à condição de Casa Escolar Pública. Além dessa, houve outra particularidade: a professora era formada pela Escola Normal Regional Nossa Senhora do Belém de Guarapuava. A regra geral da época era que apenas moças ricas, filhas de fazendeiros, estudassem em internatos. Genoveva Boiarski não era de família rica e foi a primeira filha de colonos radicados em Cascavel a cursar escola normal, no sistema de internato ${ }^{27}$.

Em 1937, após a construção do campo de pouso do Correio Aéreo Nacional (CAN) e início do funcionamento da rota, Cascavel recebeu um adicional de pessoal constituído por radiotelegrafistas e outros controladores de terra dos vôos da Aeronáutica, ampliando os segmentos sociais escolarizados e interessados na escola. Em 1938, após Cascavel ser 
elevada à condição de distrito administrativo de Foz do Iguaçu, foi criada a Casa Escolar Pública. Em 1947, após a transformação da Casa Escolar em Grupo Escolar, o Estado passou a manter a escola e pagar os professores ${ }^{28}$.

Toledo e os numerosos municípios que se desmembraram dele, foram fundados pela ação da colonizadora Maripá e têm uma história muito semelhante. Em 1946, prestava serviço na paróquia de Foz do Iguaçu o padre italiano Antônio Patuí. A convite da colonizadora, estabeleceu-se em Toledo, junto com os colonos pioneiros e participou da construção de casas e da primeira igreja. Dois anos depois do início da colonização, o padre Antônio Patuí conseguiu convencer três religiosas de Curitiba a se transferir para Toledo, para fundar a primeira escola primária na área da colonizadora Maripá. Nos primeiros meses de 1948 a escola funcionou na igreja. No mesmo ano, foi inaugurado o prédio do Colégio das Irmãs, construído pela população com participação material da colonizadora. $\mathrm{Na}$ inauguração, entre diversas autoridades religiosas e militares, estava presente o Inspetor de Ensino do município de Foz do Iguaçu. Todos ficaram admirados que em pleno sertão já houvesse escola de religiosas, "um vilarejo com apenas 14 famílias"29.

Nos demais núcleos urbanos que se desenvolveram a partir da ação colonizadora da Maripá, de modo geral, seguiram nos mesmos caminhos da região - Escola dos Colonos, mais tarde transformadas em escolas municipais rurais ou escolas confessionais católicas e luteranas, onde houve assentamento de colonos descendentes de imigrantes alemães.

$\mathrm{Na}$ construção da escola dos colonos e da escola regional, Marechal Cândido Rondon apresentou características singulares. A construção da casa escolar fez parte das primeiras construções na área destinada pela colonizadora à futura vila, com material por ela cedido e mão de obra dos $\operatorname{colonos}^{30}$. A direção da colonizadora dessa época tinha interesse em construir o maior número possível de escolas. Como a maioria dos possíveis compradores de terras eram chefes de famílias novas, com filhos pequenos, a existência de escolas constituía-se em elemento favorável à propaganda dirigida da colonizadora nas localidades de origem dos colonos. A escola era vista pelos colonos como um dos elementos necessários à vida de sua família na nova terra. Muitos colonos, mesmo após a aquisição da terra, condicionavam a transferência da família à existência de escolas.

Outra particularidade nas áreas de assentamento de colonos alemães da colonizadora Maripá era quem ensinava nas escolas dos colonos. Nas áreas de colonização de descendentes de italianos e de outros grupos étnicos havia, indistintamente, professores e professoras. Nas áreas de colonização alemã, até o final da década de 1950, havia exclusivamente professores e mantiveram-se predominantes durante diversos anos na década seguinte. Com a criação das escolas de nível ginasial, os cargos de direção continuaram sendo exclusividade dos homens.

Além deste detalhe em relação às preferências de homens para docência e direção das escolas nas regiões de colonização por descendentes de alemães, merece um destaque especial os critérios seguidos na escolha de professores na Escola dos Colonos.

O professor na Escola dos Colonos era escolhido pela comunidade colonial que tinha construído a escola para seus filhos. Essa escolha envolvia uma série de questões importantes para o próprio grupo; afinal, seria a quem confiariam seus filhos para formar homens e mulheres nas suas perspectivas de vida. Segundo diversos depoimentos ${ }^{31}$, os professores eram escolhidos por consenso do grupo colonial, a partir de critérios por eles estabelecidos. Dentre os critérios citados ou traços comuns apontados, ficam evidentes o saber; a responsabilidade, entendida como dar aula mesmo, todos os dias e no horário; ensinar tudo o que soubesse; autoridade, não só no sentido de se fazer obedecer, mas no sentido moral, de fazer-se respeitar pela própria respeitabilidade pessoal, e "ser de bem", 
conceito que incluía conduta social considerada adequada, exemplar, envolvendo aspectos ético-religiosos, frequentar a igreja, ter 'bons modos' nos encontros sociais da comunidade.

Escolhido para ser professor, o membro da comunidade era praticamente "intimado" pelo grupo colonial a prestar serviço na escola. Dificilmente conseguia furtarse à responsabilidade atribuída pelo grupo. Por outro lado, ser escolhido professor, receber a incumbência de ensinar e educar representava receber um diploma de "cidadão de primeira classe", merecedor da confiança do grupo social. De fato, assim passava a ser tratado pelo núcleo colonial; como alguém especial para cada uma das famílias. Um cidadão raro, difícil de ser encontrado e, quando encontrado, não poderia ser desperdiçado.

Esse cuidado com a escolha do professor, deixa implícito também que não desejavam qualquer escola, mas uma escola de boa qualidade, isto é, que realmente ensinasse seus filhos. Contudo, nem todos os núcleos coloniais iniciais conseguiam bons professores para suas escolas. Muitos núcleos coloniais só resolveram o problema da escola e da escolarização de seus filhos alguns anos mais tarde. Frequentemente tinham que "encomendar" um professor da localidade de origem. Nestas condições, vieram para o Oeste do Paraná um bom número de professores novos, recém formados, e que atuaram no ensino por muitos anos e alguns ainda estão em atividade. Outros núcleos tiveram que contentar-se com professores "quebra galho", provisoriamente, com o que podiam dispor no momento ${ }^{32}$.

\section{Crise da escola dos colonos: novas alternativas de escolarização}

Antes do final da década de 1950, a modalidade de escola dos colonos começou a entrar em crise. Já era difícil resolver a questão do professor nos grupos coloniais pioneiros, os novos núcleos coloniais já não podiam mais contar com pessoas disponíveis, nas condições e níveis de qualificação anteriormente exigidos para o exercício do magistério.

Outro complicador foi o de que os novos núcleos coloniais já não eram tão homogêneos como os pioneiros. Entre eles já havia população de diferentes etnias e procedências. Além do mais, a partir de 1951, a região Oeste do Paraná passou a contar com quatro novos municípios, com inúmeras vilas ou núcleos populacionais que, aos poucos foram crescendo e, nos anos seguintes, tornaram-se sede de novos municípios.

Nesses núcleos populacionais que se tornaram sedes de novo municípios, as transformações das estruturas educacionais foram em tudo muito semelhantes: Escolas dos Colonos, Grupo Escolar Municipal, Grupo Escolar Estadual depois da emancipação.

Contudo, uma das características mais gerais foi a extinção das Escolas dos Colonos, transformadas em Escolas Rurais Municipais que permaneceram com muitas das anteriores características. Como o município também não dispunha de pessoal habilitado e qualificado, obrigou-se designar "alguém" para assumir a escola, gerando frequentes descontentamentos entre os colonos quanto à perspectiva do ensino, diferente do que desejavam - a competência técnica da escola.

O descontentamento com a situação da educação levou os colonos a buscarem alternativas: mobilizaram-se para a construção de inúmeras escolas confessionais. Os colonos entendiam que esses educandários teriam professores de seus próprios quadros, resolvendo as dificuldades da falta de professores habilitados e qualificados para o ensino de boa qualidade. Nesta perspectiva é que, na região Oeste do Paraná, no período de 1955 a 1965 foram fundados diversos estabelecimentos de ensino confessionais. Algumas dessas escolas iniciaram suas atividades oferecendo o ensino primário, mas logo em seguida 
passaram a oferecer também o nível ginasial. Outras ofereceram, desde o começo, a escolaridade de nível primário e ginasial; outras, especialmente Maristas e Lassalistas, ofereciam o ginasial comercial, transformado, depois da LDB 4.024/61 em Curso Técnico em Contabilidade. Em 1957, o Colégio das Irmãs de Foz do Iguaçu implantou a Escola Normal Colegial, primeiro estabelecimento do Oeste do Paraná a ofertar este nível de escolaridade, específico para a formação de professores para o ensino primário ${ }^{33}$.

À medida que o interior dos municípios foi sendo colonizado, aí foi reivindicada escola. Os colonos das linhas e travessões construíram sua escola, mas manutenção e o pagamento do professor era responsabilidade municipal. De modo geral o município apenas conseguia proporcionar uma escola multisseriada, carente de todo o tipo de material didático e a professora insuficientemente habilitada ou sem habilitação alguma. Nas serrarias, normalmente a escola era construída pela madeireira e mantida pelo município, no mesmo sistema e condições da escola dos colonos das linhas e travessões. Apenas nos núcleos populacionais mais desenvolvidos no interior dos municípios e nas sedes urbanas existiam grupos escolares, com seriação, professores habilitados, pagos pelo poder público ou pelas organizações religiosas.

Embora já existissem na década de 1950 algumas escolas públicas e privadas de nível ginasial, e colegial em apenas uma cidade da região, a década de 1960 foi marcada pela demanda desses níveis de ensino. $\mathrm{O}$ atendimento só foi estendido pelo poder público estadual na segunda metade ou no final da década de 1960. Desta forma, é possível afirmar que, no Oeste do Paraná, na década de 1960, começou a tomar corpo e definir-se uma estrutura educacional. No período, além dos 18 núcleos urbanos, sede dos municípios, neles existindo grupos escolares públicos, confessionais e particulares, grupos escolares municipais nas principais vilas do interior dos municípios, a população urbana passou a reivindicar outros níveis de escolarização a partir da ampliação e complexificação das relações sociais já estabelecidas na região.

A década de 1960 foi marcada pela implantação de escolas de nível ginasial, públicas e privadas; de Escolas Normais Colegiais (pública só em Cascavel) e particulares; de Escolas de Contabilidade exclusivamente particulares, e de um único Curso Científico público, em Cascavel. Desta forma, no final da década de 1960, todas as sedes urbanas dos municípios do Oeste do Paraná tinham o nível ginasial de escolarização, inclusive alguns distritos mais populosos. Alguns municípios mais importantes tinham Escola Técnica de Contabilidade, Escola Normal Colegial e Curso Científico.

No mesmo período, as famílias em melhores condições econômicas mandavam seus filhos para outras cidades para cursarem uma boa escola de nível Ginasial e um bom Segundo Ciclo que garantisse acesso à escolarização de nível superior. Aos demais segmentos da população regional restavam apenas alternativas locais, isto é, reivindicar esses níveis de escolarização. Para o trabalho urbano, no comércio, em bancos e nos serviços públicos essa escolarização era necessária e a condição de acesso para ocupar as oportunidades de trabalho mais remunerado e os espaços de expressão política e de conceituação social.

À medida que os jovens dos principais centros urbanos do Oeste do Paraná concluíam a escolarização equivalente ao atual Ensino Médio, passa a ser requerido o ensino de nível superior. A década de 1970, em razão da mecanização e modernização da agricultura, intensa urbanização e modernização da economia urbana, houve um considerável aumento de demanda por mais escolarização como forma de conquista de novos espaços sociais de trabalho da população rural urbanizada. A intensa demanda por escolarização requeria também um crescente número de professores habilitados e 
qualificados para o exercício do magistério na escola em expansão. Nesse contexto é que foram implantados os primeiros Cursos Superiores do Oeste do Paraná.

A implantação do ensino superior em Cascavel, em 1972, (cursos superiores pioneiros do Oeste do Paraná) teve como fundamento diversos fatores. Entre eles: já existia um considerável número de jovens que tinham concluído a escolarização média, portanto, candidatos em potencial do ensino superior. O segmento social de maior poder aquisitivo encaminhava seus filhos para centros urbanos que tivessem ensino superior. Muitos dos estudantes da região, depois de formados, conquistavam bons espaços sociais de trabalho em outros centros urbanos e não retornavam à região. O considerável desenvolvimento urbano de Cascavel e, consequentemente, o aumento e complexificação das relações sociais, justificavam a criação do ensino superior. O segmento social intermediário, com dificuldade para manter seus filhos em outras cidades, percebia que eles não teriam outras possibilidades de conquista de espaço social de trabalho sem escolarização de nível superior. Esse segmento social incentivou e deu respaldo político na mobilização para busca de alternativas locais de ensino superior.

O ensino superior do Oeste do Paraná é um espelho da história da própria região. A ocupação e colonização da região só foram possíveis porque um povo desbravador, dentro dos limites de suas condições histórico-culturais, se dispôs a realizá-las. Na década de 1970, os centros urbanos mais desenvolvidos da região sentiam necessidade, a partir de seu próprio desenvolvimento histórico, de ampliar as condições e os níveis de escolaridade de sua juventude.

Mesmo que agentes educacionais regionais e as mais legítimas representações civis tivessem tentado diferentes saídas, ao Oeste do Paraná não sobrou alternativa senão a constituição de Fundações Municipais para manutenção de seu ensino superior. Em última instância, as comunidades locais criaram todas as condições, com participação e doações, para manutenção do ensino superior no Oeste do Paraná.

Ainda na primeira metade da década de 1980, agentes sociais, educacionais e formadores de opinião perceberam que, mantidos por fundações municipais e mensalidades de alunos, os cursos superiores do Oeste do Paraná não teriam como crescer e ampliar o leque de aspirações profissionais da juventude regional.

Neste contexto é que foram buscadas novas alternativas e possibilidades. Um aspecto típico da cultura, do comportamento da população regional, é a busca de "saídas" de forma associativa, como já tinham feito os colonos na busca de soluções para resolver problemas de produção, estocagem e comercialização de excedentes agrícolas, com a falta de estradas, de escolas e hospitais.

\section{Referências}

EMER, Ivo Oss. Desenvolvimento histórico do Oeste do Paraná e a construção da escola. Rio de Janeiro: IESAE/FGV. Mímeo, 1991.

Colodel, José Augusto. Obrages e companhias colonizadoras. Cascavel: Assoeste, 1988.

SAATKAMP, Venilda. Desafios, lutas e conquistas: história de Mal. Cândido Rondon. Cascavel: Assoeste, 1985.

SILVA, Oscar e outros. Toledo e sua história. Toledo: Prefeitura Municipal, 1988. Projeto de Reestruturação do Colégio Estadual Francisco Mendes Gonçalves de Guaíra. 


\section{Depoimentos}

Airton José Gassen. Depoimento prestado a Ivo Oss Emer, em Cascavel, em 1990

Alvina Pompeu Reis. Depoimento prestado a Ivo Oss Emer, em 1990.

Elfrida Engel Nunes Rios. Depoimento prestado a Ivo Oss Emer, em Foz do Iguaçu, 1990.

Maria Maier - Depoimento prestado a Ivo Oss Emer, em Catanduvas, 1990.

Milano Adolfo Scheidt. Depoimento prestado a Ivo Oss Emer em Cascavel, em 1990.

Stanislava Boiarski Bartinik. Depoimento prestado a Ivo Oss Emer, em Cascavel - 1990, irmã da Prof ${ }^{a}$. Genoveva.

\section{Notas}

${ }^{1}$ O presente texto é uma síntese de parte de um Capítulo da Dissertação em nível de Mestrado, pesquisa concluída em 1991 e defendida no Instituto de Estudos Avançados em Educação - IESAE - Fundação Getúlio Vargas - Rio de Janeiro, aprovada pela banca - nota 10, com louvor. A referida obra, mesmo que provisoriamente, tem a seguinte referência bibliográfica: EMER, Ivo Oss. Desenvolvimento histórico do Oeste do Paraná e a construção da escola. Rio de Janeiro: IESAE/FGV. Mímeo, 1991.

\footnotetext{
${ }^{2}$ Mestre em Educação pelo IESAE/FGV.
}

${ }^{3}$ Elfrida Engel Nunes Rios, alfabetizada em Vila Rica, Paraguai, nos anos 1912/14. Depoimento prestado a Ivo Oss Emer - Foz do Iguaçu, 1990.

${ }^{4}$ Idem - Não soube informar se, no período, a instrução Domiciliar Particular era paralela à instrução da Casa Escolar ou para crianças que não freqüentavam a Casa Escolar.

${ }^{5}$ Colodel, José Augusto. Obrages e companhias colonizadoras. Cascavel: Assoeste, 1988, p. 243 - 247.

${ }^{6}$ Idem, ibidem.

${ }^{7}$ Em 1926, a paróquia de Foz do Iguaçu foi elevada à categoria de Curato e o Padre Guilherme recebeu o título eclesiástico de Monsenhor. Idem Colodel.

${ }^{8}$ Informações colhidas na documentação da Secretaria do Colégio Estadual Bartolomeu Mitre, Foz do Iguaçu; Ivo Oss Emer, 1990.

${ }^{9}$ Colodel. op. cit. p. 245 e ss.

${ }^{10}$ Informações e descrição colhidas pelo autor no Departamento de Educação da Prefeitura Municipal de Santa Helena, em 1990.

${ }^{11}$ Colodel, op. cit. p. 248.

${ }^{12}$ Idem, idem.

${ }^{13}$ A escola de travessão não ocorreu apenas em Santa Helena, mas em diversas localidades da região durante o processo de colonização.

${ }^{14}$ Informações colhidas pelo autor na Secretaria Municipal de Santa Helena, em 1990.

15 Idem.

${ }^{16}$ Empresa que explorava a erva mate nativa no atual Mato Grosso do Sul e escoava a produção pelo rio Paraná. 
${ }^{17}$ Saatkamp, Venilda. Desafios, lutas e conquistas: história de Mal. Cândido Rondon. Cascavel: Assoeste, 1985, p: 31 .

${ }^{18} \mathrm{Na}$ época, as Cataratas do Iguaçu tornaram-se cada vez mais conhecidas e visitadas pelos brasileiros.

${ }^{19}$ Informações obtidas pelo autor na Secretaria Municipal de Educação de Guaíra em 1990, em reunião com os professores do órgão. À medida que eram formuladas perguntas e não havendo documentação a respeito, os professores buscavam informações junto a pessoas da cidade que podiam esclarecer as dúvidas.

${ }^{20}$ Preâmbulo (síntese histórica) do Projeto de Reestruturação do Colégio Estadual Francisco Mendes Gonçalves de Guaíra - Secretaria do Estabelecimento, pesquisa realizada pelo autor em 1990.

${ }^{21}$ Depoimento prestado ao autor por Elfrida Engel Nunes Rios, em Foz do Iguaçu, 1990.

${ }^{22}$ Histórico do Estabelecimento - pesquisa realizada pelo autor em 1990 - Secretaria do Colégio Estadual Mendes Gonçalves de Guaíra.

${ }^{23}$ Prof $^{\mathrm{a}}$. Alvina Pompeu Reis - professora da escola integralista de Catanduvas, depoimento prestado ao autor em 1990.

${ }^{24}$ Prof $^{\mathrm{a}}$. Alvina Pompeu Reis - depoimento citado.

${ }^{25}$ Prof $^{\text {a }}$. Maria Maier - depoimento prestado ao autor, em Catanduvas, 1990.

${ }^{26}$ Prof $^{\mathrm{a}}$. Maria Maier - depoimento citado.

${ }^{27}$ Depoimento prestado ao autor, em Cascavel - 1990, pela Prof ${ }^{a}$. Stanislava Boiarski Bartinik, irmã de Genoveva.

${ }^{28}$ Idem - depoimento citado.

${ }^{29}$ Silva, Oscar e outros. Toledo e sua história. Toledo: Prefeitura Municipal, 1988, p. 277.

${ }^{30}$ Saatkamp, op. cit., p. 87.

31 Gassen, Airton José. Depoimento colhido pelo autor em Cascavel, em 1990. Outros depoimentos semelhantes foram obtidos de outras pessoas. Este foi o mais completo.

${ }^{32}$ Milano Adolfo Scheidt. Depoimento colhido pelo autor em Cascavel, em 1990. Veio para Nova Santa Rosa a convite, para ser professor, após concluir a Escola Normal Colegial no Rio Grande do Sul.

${ }^{33}$ Informações colhidas pelo autor no Núcleo Regional de Foz do Iguaçu, em 1990.

Recebido em: $\quad 13.04 .12$

Aprovado em: $\quad 30.05 .12$ 